University of Wollongong

Research Online

Faculty of Engineering and Information

Faculty of Engineering and Information

Sciences - Papers: Part A

Sciences

$1-1-2015$

Coupled discrete element-finite difference method for analysing the loaddeformation behaviour of a single stone column in soft soil

Buddhima Indraratna

University of Wollongong, indra@uow.edu.au

Ngoc Trung Ngo

University of Wollongong, trung@uow.edu.au

Cholachat Rujikiatkamjorn

University of Wollongong, cholacha@uow.edu.au

Scott W. Sloan

University of Newcastle

Follow this and additional works at: https://ro.uow.edu.au/eispapers

Part of the Engineering Commons, and the Science and Technology Studies Commons

Research Online is the open access institutional repository for the University of Wollongong. For further information contact the UOW Library: research-pubs@uow.edu.au 


\title{
Coupled discrete element-finite difference method for analysing the load- deformation behaviour of a single stone column in soft soil
}

\begin{abstract}
Experimental studies and numerical modelling of the deformation of soft clay stabilised by stone columns have been conducted over the past few decades. Continuum-based numerical models have provided valuable insight into the prediction of settlement, lateral deformation, and stress and strain-rate dependent behaviour of stone columns at a macroscopic scale, but because they consist of granular material such as crushed rock, gravel, and waste rock aggregates, their behaviour is influenced by interparticle micromechanics and cannot be modelled properly using these models. In this paper a novel coupled model of the discrete element method (DEM) and finite difference method (FDM) is presented to study the deformation of a single stone column installed in soft ground. In this coupled discretecontinuum method, PFC2D and FLAC were used to model the interaction between the stone column and surrounding clay, respectively. The contact forces at the interface between the two zones were determined through a socket connection that allows the DEM to transfer forces and moments to the FDM and vice versa. The predicted results were comparable to the data measured experimentally, showing that the coupled discrete-continuum model proposed in this study could simulate the load-deformation behaviour of a stone column installed in clay. The contact force distribution and shear stress contour developed in the stone column and surrounding clay were captured to provide a better understanding of the load-deformation behaviour of the stone column.
\end{abstract}

\section{Keywords}

soil, soft, column, stone, single, behaviour, discrete, deformation, coupled, load, analysing, method, difference, finite, element

\author{
Disciplines \\ Engineering | Science and Technology Studies
}

\section{Publication Details}

Indraratna, B., Ngo, N. Trung., Rujikiatkamjorn, C. \& Sloan, S. W. (2015). Coupled discrete element-finite difference method for analysing the load-deformation behaviour of a single stone column in soft soil. Computers and Geotechnics, 63 267-278.

This journal article is available at Research Online: https://ro.uow.edu.au/eispapers/3042 


\title{
Coupled discrete element-finite difference method for analysing the load-deformation behaviour of a single stone column in soft soil
}

\author{
Buddhima Indraratna, PhD (Alberta), FTSE, FIEAust., FASCE
}

Research Director, Professor of Civil Engineering, Centre for Geomechanics and Railway Engineering, Faculty of Engineering, University of Wollongong, Wollongong, NSW 2522, Australia. ARC Centre for Excellence for Geotechnical Science and Engineering, Australia

Ngoc Trung Ngo, PhD, MEng, BEng

Lecturer, Centre for Geomechanics and Railway Engineering, Faculty of Engineering, University of Wollongong, Wollongong City, NSW 2522, Australia; ARC Centre for Excellence for Geotechnical Science and Engineering, Australia Faculty of Engineering, Australia

\section{Cholachat Rujikiatkamjorn, PhD, MEng, BEng}

Associate Professor, Centre for Geomechanics and Railway Engineering, Faculty of Engineering, University of Wollongong, Wollongong City, NSW 2522, Australia; ARC Centre for Excellence for Geotechnical Science and Engineering, Australia Faculty of Engineering, Australia

\section{Scott W. Sloan, PhD, FAA, FTSE}

Director, ARC Centre of Excellence for Geotechnical Science and Engineering, Laureate Professor of Civil Engineering, The University of Newcastle, NSW 2308, Australia

Submitted to: Computers and Geotechnics

Author for correspondence:

Prof. B. Indraratna

Faculty of Engineering

University of Wollongong

Wollongong, NSW 2522

Australia.

Ph: +61242213046

Fax: +61 242213238

Email: indra@uow.edu.au 


\title{
Coupled discrete element-finite difference method for analysing the load-deformation behaviour of a single stone column in soft soil
}

\author{
Buddhima Indraratna ${ }^{1}$, Ngoc Trung Ngo ${ }^{2}$, Cholachat Rujikiatkamjorn ${ }^{3}$, and Scott W. Sloan ${ }^{4}$
}

\begin{abstract}
${ }^{1}$ Research Director, Professor of Civil Engineering, Centre for Geomechanics and Railway Engineering, Faculty of Engineering and Information Sciences, ARC Centre of Excellence for Geotechnical Science and Engineering, University of Wollongong, Wollongong, NSW 2522, Australia. Email: indra@uow.edu.au, Ph: +61 242213046 Fax: +61 242213238

${ }^{2}$ Lecturer, Centre for Geomechanics and Railway Engineering, Faculty of Engineering and Information Sciences, ARC Centre of Excellence for Geotechnical Science and Engineering University of Wollongong, Wollongong, NSW 2522, Australia. Email: trung@uow.edu.au, Ph: +61242214892 Fax: +61242213238
\end{abstract}

${ }^{3}$ Associate Professor, Centre for Geomechanics and Railway Engineering, Faculty of Engineering and Information Sciences, ARC Centre of Excellence for Geotechnical Science and Engineering, University of Wollongong, Wollongong, NSW 2522, Australia. Email: cholacha@uow.edu.au, Ph: +61 242215852 Fax: +61 242213238

${ }^{4}$ Director, ARC Centre of Excellence for Geotechnical Science and Engineering, Laureate Professor of Civil Engineering, The University of Newcastle, NSW 2308, Australia

\section{ABSTRACT}

Experimental studies and numerical modelling of the deformation of soft clay stabilised by stone columns have been conducted over the past few decades. Continuum-based numerical models have provided valuable insight into the prediction of settlement, lateral deformation, and stress and strain-rate dependent behaviour of stone columns at a macroscopic scale, but because they consist of granular material such as crushed rock, gravel, and waste rock aggregates, their behaviour is influenced by inter-particle micromechanics and cannot be modelled properly using these models. In this paper a novel coupled model of the discrete element method (DEM) and finite difference method (FDM) is presented to study the deformation of a single stone column installed in soft ground. In this coupled discrete-continuum method, PFC2D and FLAC were used to model the interaction between the stone column and surrounding clay, respectively. The 
contact forces at the interface between the two zones were determined through a socket connection that allows the DEM to transfer forces and moments to the FDM and vice versa. The predicted results were comparable to the data measured experimentally, showing that the coupled discrete-continuum model proposed in this study could simulate the load-deformation behaviour of a stone column installed in clay. The contact force distribution and shear stress contour developed in the stone column and surrounding clay were captured to provide a better understanding of the load-deformation behaviour of the stone column.

\section{Introduction}

The increasing value of land and the limited availability of suitable sites for construction are driving engineers to apply appropriate ground improvement techniques to weak soil deposits. The use of stone columns is one of the most commonly adopted methods, and they have been employed worldwide to increase the bearing capacity of soft soils and decrease the long term settlement of superstructures. The main purpose of a stone column system are: (i) to transmit foundation loads to a greater depth by a combination of side resistance and end bearing, (ii) to decrease the total and differential settlements, (iii) to decrease the liquefaction potential of fine grained soils, and (iv) to decrease the drainage path for soft soil through radial consolidation under foundation loading (Barksdale and Bachus 1983; Schweiger and Pande 1986; Almgir et al. 1996; Tan et al. 2008; Deb and Dhar 2011; Ali et al. 2012; Babu et al. 2012). The deformation of stone columns installed in clay has been the subject of an extensive number of experimental and numerical modelling studies (Poorooshasb and Meyerhof 1997; Ambily and Gandhi 2007; Chai et al. 2010; Black et al. 2011; Castro and Sagaseta 2011; Cimentada et al. 2011; Fattah et al. 2011; Sivakumar et al. 2011; Castro and Sagaseta 2012; Hanna et al. 2013, Han and Ye 2002, among others). Stone columns reduce 
the drainage paths in soft clay, which accelerates consolidation and increases the load carrying capacity due to the subsequent reduction in settlement (Guetif et al. 2007; Chai et al. 2010; Deb et al. 2011; Indraratna et al. 2013; Sivakumar et al. 2011; Ali et al. 2012; Juneja and Mir 2012; Tandel et al. 2012). Upon external loading, stone columns distribute the applied stress and deform laterally, especially in their upper zones, rather than transfer the stresses into the deeper layers. When stone columns are installed in soft clay, however, they may not increase the load bearing capacity due to the low confining pressure at shallow depths which leads to extensive bulging. Indeed, failure often occurs due to this bulging within the top part of the column.

Continuum-based numerical models have been used extensively to provide valuable insight into the behaviour of soft soils at the macroscopic scale such as settlements, lateral deformations, and stress and strain-rate dependency. However, owing to the discrete nature of stone columns, which typically consist of granular material such as crushed rock, gravel or waste rock aggregates, the discrete inter-particle micro-mechanical aspects cannot be properly modelled by a continuum approach. Furthermore, stone columns and soil media interact strongly during loading and, simulating this interaction using a coupled numerical model is a challenging task. Studies of this behaviour from a micro-mechanical perspective have been limited mainly to the load transmitted from a stone column through to the surrounding clay, with previous attempts to analyse the behaviour of the stone column itself using discrete particle-based techniques being constrained by available computational technology. A coupled DEM-FDM approach is applied here to take advantage of the strengths of each modelling scheme, as well as to minimise the computing resources required. For a unit cell analysis, the finite difference (continuum) method is used to model the surrounding clay, while the discrete element model is used to represent the stone column. Principally, coupling between the DEM and FDM can be achieved at the soil-column 
interface by: (a) treating the finite difference nodal displacements as velocity boundary conditions for the discrete elements and vice versa, and (b) by applying the forces acting on the discrete elements as force boundary conditions to the finite difference grids.

The key objective of this paper is to propose a mathematical framework to couple the discrete element method and finite difference method to numerically simulate the unit cell of a stone column. The results of the load-deformation behaviour of a stone column are studied using the proposed coupled model and then compared with data published in the literature to verify the accuracy and reliability of the model.

\section{Implementation of the coupling discrete-continuum method}

The concept of coupling the discrete-continuum method to study the deformation of a unit cell stone column is illustrated in Figure 1, where the model geometry follows the test setup described by Sivakumar et al (2011). The load-deformation behaviour of stone column is axisymmetric in nature. Given the scope of the current 2D coupled DEM-FDM analysis, an equivalent plane strain model is adopted, and Figure 1 shows a diagrammatic illustration of the conversion of axisymmetric stone column (REV) into an equivalent plane strain unit cell. The transformed deformation behaviour of an axisymmetric single stone column to its equivalent counterpart is formulated on the basis of geometric and soil permeability adjustment (Appendix 1) as proposed by Hird et al. (1992) and Indraratna and Redana (1997). Although there is no radial flow is considered during the undrained analysis, the plane strain conversion is still necessary to include the overall effect of the column-soil composite stiffness during compression. In other words, the plane-strain material stiffness still needs to be adjusted to capture the geometrical changes as described in the Appendix 1. It is also noted that the coupled DEM-FDM analysis does not include smear zone because for 
non-displacement type ground intrusions, there is no significant smear zone created, as also reported by Sivakumar et al. (2011) for a pre-bored stone column. The domain of the stone column, which is governed by discrete particle interaction, was modelled by the Discrete Element Method, using PFC2D (Itasca 2008), whereas the soft clay was simulated using the finite difference method, using FLAC (Itasca 2010). A series of walls in the DEM at the interface between the stone column and the clay were generated such that each wall corresponded to an individual continuum element at the interface in the FDM. Information at the stone column and soil interface in the coupled models were transferred as boundary conditions between the two codes using a socket Input/Output function (I/O), as shown in Figure 2. During iterations at the interface, the DEM particles transferred forces and moments to the FDM mesh, and then the FDM updated the wall displacements to the DEM particles. The element sizes at the interface in the FDM were reduced until they included several discrete particles in the DEM and the overall results were no longer affected. Upon external loading, the nodal displacements at the interface in the FDM grid were transferred to a series of walls in the DEM so that the walls could deform the same way. The wall forces resulting from the particles were then transferred to the FDM grid as applied nodal forces.

\section{Mathematical framework for coupling between a discrete particle and a continuum element}

This section presents the algorithms and governing equations developed to implement the coupling mechanism at the interface of the FDM and DEM, as shown in Figure 3a. When contact between the particles and elements has been formed, it can be described by the contact point $x_{i}^{[C]}$ lying on a contact plane defined by a unit vector $n_{i}$, which is directed along the line defining the shortest distance $d$, between the centre of the particle $x_{i}^{[B]}$ and the wall 
(Figure 3a). The overlapping distance $U^{n}$, defined as the relative contact displacement in the normal direction, is given by:

$U^{n}=R_{i}^{[B]}-d$

where, $R_{i}^{[B]}$ is the radius of particle $B$

The location of the contact point is given by:

$x_{i}^{[C]}=x_{i}^{[B]}+\left[R_{i}^{[B]}-\left(R_{i}^{[B]}-d\right) / 2\right] n_{i}$

The contact force vector at the interface, $F_{i}^{[C]}$, can be resolved into a normal force $F_{n i}^{[C]}$ and a shear force $F_{s i}^{[C]}$ with respect to the contact plane, according to:

$F_{i}^{[C]}=F_{n i}^{[C]}+F_{s i}^{[C]}$

The magnitude of the normal contact force is defined as:

$F_{n i}^{[C]}=k_{n} U^{n} n_{i}$

where, $k_{n}$ is the normal contact stiffness as determined by the contact stiffness model.

The shear contact force at any time is computed by the corresponding increment of the shear force, which can be evaluated by the relative shear displacement knowing the shear stiffness, $k_{s}$. The motion of the contacts can be determined by monitoring the updating of the normal vector $n_{i}$ and the position of contacts $x_{i}^{[C]}$ in each time step. The relative contact velocity at the interface (e.g., the shear velocity of the wall relative to the particle), $V_{i}$ is given by:

$V_{i}=\dot{x}_{i, E}^{[C]}-\dot{x}_{i, B}^{[C]}$ 
where, $\dot{x}_{i, E}^{[C]}$ and $\dot{x}_{i, B}^{[C]}$ are the velocities of the continuum element and the particle at the interface, respectively. The component $\dot{x}_{i, B}^{[C]}$ is described as follows:

$\dot{x}_{i, B}^{[C]}=\dot{x}_{i, B}^{[C]}+e_{i j k} \omega_{3}^{[B]}\left(x_{i}^{[C]}-x_{i}^{[B]}\right)$

where, $\omega_{3}^{[B]}$ is the rotational velocity and $e_{i j k}$ is the permutation symbol, given by:

$e_{i j k}=\left\{\begin{array}{rr}0, & \text { if } 2 \text { indices coincide; } \\ +1, & \text { if } i, j, k \text { permute like } 1,2,3 \\ -1, & \text { otherwise }\end{array}\right.$

By assuming that the overlapping distance $U^{n}$ between the particles and continuum elements is small, the velocities of the continuum elements at the contact points can be determined by interpolating into the nodal velocities, and can be expressed as:

$\dot{x}_{i, E}^{[C]}=\sum N_{j} \dot{x}_{i, E}^{j}$

where, $\dot{x}_{i, E}^{j}$ is the nodal velocity of the continuum element $j$, and $N_{j}$ is the type function determined by:

$N_{j}=\frac{L-\sqrt{\left(x-x_{i}\right)^{2}+\left(y-y_{i}\right)^{2}}}{L} \quad(i=1,2)$

$L=\sqrt{\left(x_{1}-x_{2}\right)^{2}+\left(y_{1}-y_{2}\right)^{2}}$

The contact displacement increment at the interface per time step $\Delta t$ is given by:

$\Delta x_{i}^{[C]}=V_{i} \Delta t=\Delta x_{n i}^{[C]}+\Delta x_{s i}^{[C]}$

$\Delta x_{n i}^{[C]}=\Delta x_{i}^{[C]} n_{i}$

thus, $\Delta x_{s i}^{[C]}=\Delta x_{i}^{[C]}-\Delta x_{n i}^{[C]}=\Delta x_{i}^{[C]}-\Delta x_{i}^{[C]} n_{i}$ 
where, $\Delta x_{n i}^{[C]}$ and $\Delta x_{s i}^{[C]}$ are components of the normal and tangential vectors of the contact displacement increment, respectively.

The contact shear force increment at each time step is then determined by:

$\Delta F_{s i}^{[C]}=-k_{s} \Delta x_{s i}^{[C]}$

where, $k_{s}$ is the shear contact stiffness.

The new contact shear force component is determined by the superposition of the contact shear force increment and the shear force, as given by:

$F_{s i}^{[C]} \leftarrow \Delta F_{s i}^{[C]}+F_{s i}^{[C]} \leq \mu \Delta F_{n i}^{[C]}$

where, $\mu$ is the coefficient of friction.

The resultant force and moment on the contacted ball are then computed as:

$F_{i}^{[B]} \leftarrow F_{i}^{[B]}-F_{i}^{[C]}$

$M_{i}^{[B]} \leftarrow M_{i}^{[B]}-e_{i j k}\left(x_{j}^{[C]}-x_{j}^{[B]}\right) F_{i}^{[C]}$

where, $F_{i}^{[B]}$ and $M_{i}^{[B]}$ are the superposition of the contact forces and the moments of contact forces, respectively, on the contacted particles. The quantities $x_{j}^{[C]}$ and $x_{j}^{[B]}$ are the contact point coordinates and center coordinates of the contacted ball.

The interface elements only receive applied forces from discrete particles at their nodes $\left(F_{X A \text {, }}\right.$ $\left.F_{Y A}, F_{X B}, F_{Y B}\right)$. Therefore, a proposed schematic diagram to transfer the forces and moment from a discrete particle $\left(F_{X}, F_{Y}\right.$ and $\left.M\right)$ to the nodal forces in a continuum element is illustrated in Figure 3b. 
Considering the equilibrium of forces in the $\mathrm{x}$ and $\mathrm{y}$ directions, the vertical and horizontal forces can be determined by:

Force in the horizontal direction: $\quad F_{X}=F_{X_{A}}+F_{X_{B}}$

Force in vertical direction: $\quad F_{Y}=F_{Y_{A}}+F_{Y_{B}}$

Equilibrium in total moment at the centre of a wall can be expressed by:

$$
M=F_{Y_{A}}\left(X_{A}-X_{C}\right)+F_{Y_{B}}\left(X_{B}-X_{C}\right)-F_{X_{A}}\left(Y_{A}-Y_{C}\right)-F_{X_{B}}\left(Y_{B}-Y_{C}\right)
$$

Eqs.(18) and (19) can be described alternatively as:

$$
\begin{aligned}
& F_{X}=F_{X_{A}}+F_{X_{B}}=\Theta \times F_{X}+(1-\Theta) \times F_{X} \\
& F_{Y}=F_{Y_{A}}+F_{Y_{B}}=\Theta \times F_{Y}+(1-\Theta) \times F_{Y}
\end{aligned}
$$

in which the parameter $\Theta$ is defined as follows:

$$
\begin{aligned}
& F_{X_{A}}=\Theta \times F_{X} \quad \text { and } \quad F_{Y_{A}}=\Theta \times F_{Y} \\
& F_{X_{B}}=(1-\Theta) \times F_{X} \text { and } F_{Y_{B}}=(1-\Theta) \times F_{Y}
\end{aligned}
$$

Substituting Eqs. (23) and (24) in to Eq.(20) gives:

$$
\begin{aligned}
& M=\Theta \times F_{Y} \times\left(X_{A}-X_{C}\right)+(1-\Theta) \times F_{Y} \times\left(X_{B}-X_{C}\right)-\Theta \times F_{X} \times\left(Y_{A}-Y_{C}\right)-(1-\Theta) \times \\
& F_{X} \times\left(Y_{B}-Y_{C}\right)
\end{aligned}
$$

or:

$$
\Theta=\frac{M-F_{Y} \times\left(X_{B}-X_{C}\right)+F_{X} \times\left(Y_{B}-Y_{C}\right)}{F_{Y} \times\left(X_{A}-X_{B}\right)-F_{X} \times\left(Y_{A}-Y_{B}\right)}
$$


Eq. (26) can be combined with Eqs. (23) and (24) to transfer forces and moments from the DEM to the FDM model as force boundary conditions at nodal points of the continuum mesh. Subroutines, written in the FISH language, were developed by the Authors in order to incorporate all the aforementioned Equations to implement a fully coupled DEM-FDM simulation.

\section{Determination of micro-mechanical parameters}

It is believed that the particle shape is a key factor affecting the mechanical properties of granular materials and influencing the redistribution of stresses within the granular assembly. Given the scope of the current DEM analysis, circular particles between $1.5 \mathrm{~mm}$ to $3 \mathrm{~mm}$ in diameter were simulated to model the stone column. Stone column material is crushed stone and that individual circular particles in PFC-2D code cannot represent highly angular particles. However, the irregularly-shaped particles are modeled by clumping a number of circular particles of different sizes together (clump logic in PFC). The clump behaves like a rigid body where the internal contacts are ignored (Itasca 2008). It is noted that the micromechanical parameters should ideally be determined based on the experimental data on the material itself. However, due to the lack of sufficient test data for this specific individual material, the Authors have adopted an alternative option through back-analysis of a distinct test (20-mm column model) to obtain the appropriate micro-mechanical parameters for the DEM simulation (i.e. based on the load-deformation response of the stone column). The micro-mechanical parameters adopted for the DEM model are given in Table 1, and were determined based on their calibration with the experimental data reported by Sivakumar et al. (2011). Initially, a set of micro-mechanical parameters (stiffness, inter-particle friction coefficient, etc.,) used for DEM simulation of a 20mm-diameter stone column was assumed. The coupled DEM-FDM was then performed, and the simulated settlement corresponding to 
the applied vertical stress was then compared to the experimental data reported by Sivakumar et al. (2011). An appropriate set of micro-mechanical parameters was adopted for the stone column, when a reasonable agreement between the prediction and measurement was achieved and the numerical procedure thereby calibrated with the observed data. Stone columns with diameters of $D=20,25$, and $30 \mathrm{~mm}$ were modelled in the DEM. To simulate the elasto-plastic behaviour of the surrounding clay, the Mohr-Coulomb failure criterion was adopted. The surrounding clay was assumed to be undrained and a total stress analysis was conducted. The input parameters of the surrounding clay are given in Table 2. It is believed that a proper undrained analysis can be conducted in terms of effective stresses. However, $100 \%$ fully saturated and undrained situations are rare in the field and it is almost impossible to get a perfectly zero friction angle. Therefore, the assumption of a small undrained friction angle of $5^{0}$ is reasonable. This approach has been implied for undrained stability analysis, and often the adopted practice in industry. In our view, this is more realistic than an idealised condition using $\phi_{u}=0$, knowing that the in-situ soil is not $100 \%$ saturated. Therefore, an undrained cohesion of $22 \mathrm{kPa}$ and an undrained friction angle of $5^{0}$ have been used for the current coupled DEM-FDM analysis. The total number of particles generated to model stone columns with diameter of $D=20,25$, and $30 \mathrm{~mm}$ are 3162, 3980, and 4742, respectively. Using a workstation, Dell T7500, the total calculation times for generating DEM models and running coupled DEM-FDM analysis are approximately 8.5 hours, 11 hours and 13.5 hours for simulating stone columns with diameter of $D=20,25$, and $30 \mathrm{~mm}$, respectively. 


\section{Validation of DEM-FDM coupling model}

\subsection{Vertical stress versus settlement}

Experimental data reported by Sivakumar et al. (2011) was used to validate the proposed coupling model. A schematic diagram of the coupling model is shown in the Figure 1, where a cylindrical specimen of clay using an axisymmetric element was used to simulate the triaxial conditions.

To implement a coupling model, the following three sequential steps were used: (i) a DEM model for the stone column was generated using PFC2D and cycled to bring the assembly to initial equilibrium, (ii) a continuum mesh was then created for the FDM to model the surrounding clay with a predetermined geometry (Figure 1), with the input parameters given in Tables 1 and 2, and (iii) once the setup process was completed, a load was applied to the top of the column and iterations were carried out in both methods. These iterations were synchronised by using a time step of unity so that the displacements and forces for each time step could be calculated and updated. Time steps in the coupled DEM-FDM are implemented based on an explicit "time-marching” finite difference solution scheme. The time steps for both DEM and FDM can vary, because, mesh size changes in the FDM region and particle contact stiffness are connected with the relative positions between the particles in the DEM domain. The computed solution produced by the coupled DEM-FDM remains stable only if the time step does not exceed a critical value that is related to the minimum Eigen period of the total system (Itasca, 2008). Hence, the stability criterion for the numerical scheme must provide an upper bound for the values of the time steps used in the finite difference scheme. In this study, a simplified procedure introduced by Bathe and Wilson (1976) has been implemented in the coupled DEM-FDM model to estimate the critical time step at the start of each cycle, given by: 
$t_{c r i t}=\sqrt{\frac{m}{k}}$

where, $m$ and $k$, are the mass and stiffness of the particle, respectively. The iteration time step of DEM and FDM is identical which is achieved by running FLAC in static mode and PFC2D with differential density scaling so that the time step is in unity for both processes.

When the bulging occurs, the re-meshing is required in the FDM model to avoid large distortion. Automatic re-meshing (or rezoning) logic for large- strain models (e.g., involving large displacement, displacement gradients and rotations) is adopted in the current analysis. As bad-zone geometries threaten the convergence of the model, automatic re-meshing performs a re-mapping of zones, while preserving accuracy in the calculations, to restore integrity to the mesh and allow further cycling (Itasca 2010). In this approach, the velocity of a node is assumed to vary linearly over a time interval $t$, and the node location is updated using the central finite difference approximation:

$x_{i}(t+\Delta t)=x_{i}(t)+\Delta t v_{i}\left(t+\frac{\Delta t}{2}\right)$

The vertical settlement and applied pressure were monitored during the loading process. Figure 4 shows the plots of applied vertical pressure versus settlement obtained by the coupling model and the laboratory data reported by Sivakumar et al. (2011). Here the simulated pressure versus settlement curves predicted the trends in the laboratory measurements quite well, although the coupling analysis showed some discrepancy especially within the settlement range of 5-10 mm. Although the exact causes for these disparities were not immediately clear, they were possibly associated with uncertainties in the model tests and limitations in the numerical simulations, where particles with irregular shape needed to be simulated more accurately. 


\subsection{Stress distribution along the stone column}

Figure 5 compares the evolution of the vertical stress within the stone column based on the results obtained from the numerical simulations and those measured experimentally by Sivakumar et al. (2011). These comparisons are at locations PC1, PC2, and PC3 which are located at the top, middle and bottom of the stone column, respectively. The vertical stresses at the three different locations predicted by the numerical simulations generally agree with those measured experimentally, and increase with an increase in settlement. As expected, these stresses decreases with depth, primarily as a result of the load transfer mechanism between the column and the surrounding clay. The load in the column is transferred to the surrounding clay as the lateral stresses increase, causing bulging and mobilising friction at the interface. In addition to this, the predicted vertical stresses close to the base of the stone column (PC3) are slightly more than those measured at the intermediate depth (PC2). This result could be associated with the boundary condition constraint at the base combined with the high interlocking forces caused by consolidation. Not surprisingly, there is some disparity in the vertical stresses between the numerical predictions and the laboratory data. This can be attributed to the difference in particle shape between the DEM simulation and the laboratory observations, as well as particle degradation, an aspect which was not considered in the current analysis.

\subsection{Lateral deformation of stone column obtained from coupled DEM-}

\section{FDM simulation}

It is well known that a single stone column deforms and fails due to bulging which forms in the upper portion of the column. Figure 6 shows the predicted lateral deformation profile of the three stone columns with depth, at the end of the loading program. The displacement profiles obtained from the numerical simulations confirm that a single stone column will 
bulge under applied load. The magnitude of this lateral deflection tends to increase sharply as the diameter of the column decreases. The bulging region extends down to $110 \mathrm{~mm}$ from the ground surface but, beyond a depth of around $40 \mathrm{~mm}$, at which the maximum outward lateral displacement occurs, the extent of the bulging decreases with depth. This observation supports the argument that bulging increases the lateral confinement and shear stresses in the upper part of the column which causes the surrounding clay to settle. Bulging that leads to large deformation results in significant changes in the contact force distribution within the granular assembly of the stone column.

\subsection{Contact force distribution in the stone column and shear stress}

\section{contours developed in the clay}

Figure 7 illustrates the contact force distributions for the $20 \mathrm{~mm}$ diameter stone column at various settlements, $S$, ranging from 0 to $15 \mathrm{~mm}$. The contact forces between the particles are plotted as lines whose thickness is proportional to their magnitude. For the purpose of clarity, only those contact forces with a magnitude exceeding the average value in the upper part of the stone column were plotted, and they clearly show that the total number of contact forces and maximum contact forces increases with increasing settlement, mainly because the column compresses to sustain the external load and bulges into the surrounding clay. Moreover, when the loading process ceased (i.e. at the settlement of $S=15 \mathrm{~mm}$ ) the number of contact forces and maximum contact force (Figure 7d) are both slightly lower than those estimated at smaller settlements. These results could be related to the extensive bulging of the stone column and the associated reduction in its bearing capacity.

The shear stresses that are induced developed in the surrounding clay by bulging are generally difficult to measure in the laboratory or the field, as in-situ pressure cells tend to be damaged by the sharp edges of the aggregates at the interface. However, these shear 
stresses can readily be obtained via numerical simulation and are presented herein. Figure 8 illustrates the contours of shear stress, at two settlements of $5 \mathrm{~mm}$ and $15 \mathrm{~mm}$, that were developed in the surrounding clay reinforced by the $20 \mathrm{~mm}$ diameter stone column. As expected, the shear stress is non-uniform in the clay, and its magnitude depends on the vertical and lateral displacements, i.e. the level of bulging. Indeed, the shear stress contours are concentrated near the upper part of the stone column where bulging occurred. It is noted that the maximum shear stress has occurred within the bulging region and its magnitude increases as the column settlement increases. The maximum shear stresses developed in the clay at a settlement of $15 \mathrm{~mm}$ are much greater than those at a settlement of $5 \mathrm{~mm}$ (i.e. 16 $\mathrm{kPa}$ compared to $8 \mathrm{kPa}$, respectively). This may be caused by the increased lateral bulging effect of the stone column which is resisted by the frictional stresses mobilised at the interface with the surrounding clay. Shear strains developed across the surrounding clays at two varying settlements of $5 \mathrm{~mm}$ and $15 \mathrm{~mm}$ are presented in Figure 8c and 8d, respectively. It can be seen that most of the clay movement occurs near the upper zone of the column leading to bulging in that area. Lateral deformation of surrounding clay considerably decreases with depth of the column and becomes presumably negligible below the two-third of the column length from the ground surface.

\section{Model Limitations}

The coupled DEM-FDM presented in this paper is able to capture the load-deformation behaviour of soft clays which are stabilised by stone columns. However, the current coupling analysis still has several limitations which require further study, as mentioned below:

- Further investigation should be conducted to fully capture the time-dependent behaviour of stone column and clay, and their interaction, such as the dissipation of 
excess pore pressure and the clogging phenomenon at the interface between stone column and the surrounding clay.

- Aggregates of highly angular shaped should be modelled to provide a better understanding of the load-deformation behaviour from a micro-mechanical perspective, including contact force orientations, particle displacement vectors, and their changes associated with the bulging of the upper part of column. 


\section{Conclusion}

A mathematical framework for coupling finite difference and discrete element methods in order to model stone column reinforced soft clay was introduced in this study. The stone column was modelled using the discrete element method (DEM) while the soft clay was simulated using the finite different method (FDM). In the numerical simulation, full coupling between the DEM and the FDM was implemented via a built in socket connection developed by the Authors. This model combines the advantages of the discrete and continuum methods and facilitates the exchange of interface contact forces and displacements between the discrete and continuum boundaries. The contact forces and moment at the interface were obtained from the discrete domain and transferred to the continuum zone as nodal forces, while the interface displacements were obtained from the continuum boundaries and transferred to the discrete zone via the "socket" connection. The following conclusions can be drawn from the observed results of the DEM-FDM simulation.

- The results of applied stress versus settlement were comparable with the experimental data, indicating that the coupled model proposed in this study could capture the loaddisplacement behaviour of soft clay reinforced with stone columns. As the diameter of the column is increased, the failure stress of the column-reinforced clay system is increased, while the lateral deformation is decreased.

- The contact force distribution and the shear stress contours developed in the stone column and surrounding clay, respectively, were modelled to better understand the bulging behaviour of the column. The total number of contact forces and the maximum contact force increased with an increase in settlement, and this is attributed to the column compressing under the external load and the associated bulging of the upper part of column into the surrounding clay. When the loading process ended, the 
number of contact forces and maximum contact forces had slightly were lower than those observed for smaller settlements. These results could be related to excessive bulging of the stone column and its reduced bearing capacity. It was also noted that the maximum shear stress occurred within the bulging region and its magnitude increased with the column settlement.

The proposed coupled DEM-FDM model can provide a fundamental numerical framework to inspire further studies of the load-deformation behaviour of soft soils stabilised by stone columns. Further work is envisaged to reduce the limitations of the current study while still employing micro-mechanical analysis. 


\section{Appendix 1: Conversion from Axisymmetric to Equivalent Plane Strain Model}

Hird et al. (1992) proposed a method for matching plane strain and axisymmetric analyses by manipulating the drain spacing and soil permeability, and a similar approach is adopted for the current analysis. For this purpose, a plane strain unit cell of a single stone column of depth $L$, width $2 B$, with a discharge flow $F_{w}$ per unit length (Figure 9) is considered. For matching the rate of deformation between axisymmetric and plane strain condition, the following geometric transformation is established:

$\frac{B}{R}=\sqrt{\frac{3}{2}\left[\ln \left(\frac{R}{r_{s}}\right)+\frac{k}{k_{s m}} \ln \left(\frac{r_{s}}{r_{c}}\right)-\frac{3}{4}\right]}$

where, $R, r_{c}, r_{s}$ are the radius of the axisymmetric unit cell, the column, and the smear zone, respectively. $k$ and $k_{s m}$ are the horizontal permeability of the undisturbed and smeared soil, respectively.

To ensure the matching of pore water pressure and volume change conditions, the method of manipulating the soil permeability (Indraratna and Redana, 1997) has been adopted. For simplicity, assuming $B=R$ the following condition is obtained:

$\frac{k_{p l}}{k_{a x}}=\frac{2}{3\left[\ln \left(\frac{R}{r_{s}}\right)+\left(\frac{k_{a x}}{k_{s m}}\right) \ln \left(\frac{r_{s}}{r_{c}}\right)-\frac{3}{4}\right]}$

where, the subscripts $a x$ and $p l$ denote axisymmetric and plane strain conditions, respectively.

The plane-strain material stiffness need to be adjusted to account for the geometrical changes (Tan et al. 2008) and is determined by:

$E_{c, p l} a_{s, p l} E_{s, p l}\left(1-a_{s, p l}\right)=E_{c, a x} a_{s, a x}+E_{s, a x}\left(1-a_{s, a x}\right)$ 
where, $E_{c}$ and $E_{s}$ are elastic moduli of the column material and the surrounding soil, respectively. Area replacement ratio is given by: $a_{s}=A_{c} /\left(A_{c}+A_{s}\right)$, where $A_{c}$ and $A_{s}$ are cross-section areas of the column and surrounding soil, respectively. In this study, for simplicity, $E_{s, p l}=E_{s, a x}$, hence $E_{c, p l}$ can be determined accordingly.

The comparison between the axisymmetric unit cell and the converted equivalent plane strain model is shown in Figure 10. This result confirms that the equivalent plane strain model can be applied in confidence to the actual axisymmetric problem.

Incorporating Eqs. (29) and (30) in the analysis, the change in volume, $\partial \varepsilon_{y}$ and corresponding average pore water pressure, $\bar{u}$ within a block of soil based on the equivalent plane strain unit cell is derived as follows.

The rate of pore water flow toward the column at distance $x$ is given by:

$v_{x}=\left(\frac{k}{\gamma_{w}}\right)\left(\frac{\partial u}{\partial x}\right)$

where, $\gamma_{w}$ is the unit weight of water; $u$ is pore water pressure.

Considering a horizontal slice of thickness $d y$, the flow at a distance $x$ from the centreline of the column is made equal to the change in volume within a representative volume of soil of width $(B-x)$, so that,

$v_{x}=\left(\frac{\partial \varepsilon_{y}}{\partial t}\right)(B-x)$

where, $\varepsilon_{y}$ is the strain in the $y$ direction.

Substituting Eq. (33) into Eq.(32) and rearranging gives the pore pressure gradient in the undisturbed soil domain as, 
$\left(\frac{\partial u}{\partial x}\right)=\left(\frac{\gamma_{w}}{k}\right)\left(\frac{\partial \varepsilon_{y}}{\partial t}\right)(B-x) ; \quad B \geq x \geq r_{S}$

In the smeared zone, the corresponding pore water pressure gradient is then given by:

$\left(\frac{\partial u^{\prime}}{\partial x}\right)=\left(\frac{\gamma_{w}}{k_{s m}}\right)\left(\frac{\partial \varepsilon_{y}}{\partial t}\right)(B-x) ; \quad r_{s} \geq x \geq r_{c}$

Integrating Eqs.(34) and (35) in the $x$-direction with the boundary conditions that at $y=$ $0, u=0$ and at $y=L, \frac{\partial u}{\partial y}=0$, gives the following equations for $u$ and $u^{\prime}$ :

$u=\frac{\gamma_{w}}{2} \frac{\partial \varepsilon}{\partial t} \frac{1}{k_{p l}}\left[x(2 B-x)+\frac{2 B}{F_{w}} \frac{k_{p l}^{2}}{k_{s m}}\left(2 L y-y^{2}\right)-r_{s}\left(2 B+r_{s}\right)\right]$

$u^{\prime}=\frac{\gamma_{w}}{2} \frac{\partial \varepsilon}{\partial t} \frac{1}{k_{s m}}\left[x(2 B-x)+\frac{2 B k_{p l}}{F_{w}}\left(2 L y-y^{2}\right)-r_{c}\left(2 B-r_{c}\right)\right]$

Incorporating Eqs.(36) and (37) in the method proposed by Indraratna and Redana (1997), the average excess pore water pressure $(\bar{u})$ across the section at depth, $y$ at a given time, $t$ can be defined as:

$\bar{u}=\frac{B^{2}}{2 k} \frac{\partial \varepsilon}{\partial t}\left[\alpha+\frac{k_{p l}}{k_{s m}} \beta+\theta\left(2 L y-y^{2}\right)\right]$

where, $\alpha=\frac{2}{3}-\frac{4}{3} \frac{r_{S}^{3}}{B^{3}}+\frac{2 r_{S}^{2}}{B^{2}}-\frac{2 r_{S}}{B}$

$\beta=\frac{r_{s}^{2}}{B^{2}}-\frac{r_{s}^{3}}{3 B^{3}}-\frac{2 r_{c}^{3}}{3 B^{3}}-\frac{2 r_{c} r_{s}}{B^{2}}+\frac{r_{c}^{2}}{B^{2}}+\frac{r_{c}^{2} r_{s}}{B^{3}} ; \quad$ and $\quad \theta=\frac{2 k_{p l}^{2}}{B F_{w}}-\frac{2 r_{c} r_{s}}{B^{2}}$

The matching rules presented in Eqs.(29), (30) and (31) and the relationship between average pore water pressure, $\bar{u}$ and the deformation, $\partial \varepsilon$ shown in Eq.38 are then incorporated into a FDM code, which follows a 2D plane strain mesh (Figure 1). 


\section{Acknowledgement}

The authors would like to express their appreciation to the Australian Research Council (ARC) for providing funding to this Project through the Arc Centre of Excellence in Geotechnical Science and Engineering and the Discovery Project. 


\section{Nomenclature}

$a_{s} \quad$ area replacement ratio

$A_{c} \quad$ cross section area of the stone column

$A_{s} \quad$ cross section area of the surrounding soil

B half width of plane strain unit celld distance between the centre of the particle and the wall

$e_{i j k} \quad$ permutation symbol

$E_{p} \quad$ modulus of elasticity

$F_{w} \quad$ water discharge flow

$F_{i}^{[C]}$ contact force vector at the interface

$F_{i}^{[B]} \quad$ superposition of the contact forces

$F_{n i}^{[C]}$ normal force at the interface

$F_{s i}^{[C]}$ shear force at the interface

$F_{X} \quad$ force on horizontal direction

$F_{X A}, F_{X B} \quad$ forces on horizontal direction at nodes $A, B$

$F_{Y} \quad$ force on vertical direction

$F_{Y A}, F_{Y B} \quad$ forces on vertical direction at nodes $A, B$

$\Delta F_{n i}^{[C]}$ contact normal force increment

$\Delta F_{s i}^{[C]}$ contact shear force increment

$\Delta t \quad$ time step 
$k \quad$ horizontal permeability of the undisturbed soil

$k_{s m} \quad$ horizontal permeability of the smear soil

$k_{p l} \quad$ permeability soil in equivalent plane strain

$k_{a x} \quad$ permeability soil in axisymmetric unit cell $k_{n}$ contact normal stiffness

$k_{s} \quad$ contact shear stiffness

$k_{n \text {-wall }}$ contact normal stiffness of wall-particle

$k_{s-w a l l}$ contact shear stiffness of wall-particle

$m$ mass of the particle $M$ moment at the centre of a wall

$M_{i}^{[B]}$ superposition of the moments of the contact forces

$n_{i} \quad$ unit vector

$N_{j} \quad$ type function

$r_{c} \quad$ radius of the column

$r_{s} \quad$ radius of the smear zone

$R \quad$ Radius of axisymmetric unit cell

$R_{i}^{[B]} \quad$ radius of particle $B$

S vertical settlement

$t_{\text {crit }}$ critical time step $V_{i}$ shear velocity of the wall relative to the particle at the interface

$v_{i} \quad$ velocity of a node

$x_{i} \quad$ node location of finite difference element $x_{i}^{[C]} \quad$ location of the contact point

$x_{i}^{[B]} \quad$ centre of the particle

$x_{j}^{[C]} \quad$ contact point coordinates 
$x_{j}^{[B]} \quad$ center coordinates of the contacted particle

$\Delta x_{n i}^{[C]}$ normal vectors of the contact displacement increment

$\Delta x_{s i}^{[C]}$ tangential vectors of the contact displacement increment

$\Delta t \quad$ time step

$\dot{x}_{i, E}^{[C]} \quad$ velocity of the element (wall) at the interface

$\dot{x}_{i, B}^{[C]} \quad$ velocity of the ball at the interface

$u \quad$ pore water pressure in the undisturbed soil

$u^{\prime} \quad$ pore water pressure in the smear soil

$\bar{u} \quad$ average pore water pressure

$U^{n} \quad$ overlapping distance

$v_{x} \quad$ rate of pore water flow

$\alpha, \beta, \theta$ dimensionless parameters

$\omega_{3}^{[B]}$ rotational velocity of the particle

$\partial \varepsilon_{y} \quad$ change in volumn

$\gamma_{c} \quad$ density of clay

$\gamma_{w} \quad$ unit weight of water

$\mu \quad$ coefficient of friction

$\checkmark \quad$ poison's ratio

$\phi_{u} \quad$ undrained friction angle

$\Theta \quad$ parameter 


\section{References}

Ali, K., Shahu, J. T. \& Sharma, K. G. (2012). "Model tests on geosynthetic-reinforced stone columns: a comparative study". Geosynthetics International,. 19(4): 292-305.

Almgir, M., Miura, N., Poorooshasb H. B. \& Madhav, M. R. (1996). "Deformation analysis of soft ground reinforced by columnar inclusions". Computers and Geotechnics. 18(4): 267-290.

Ambily, A. \& Gandhi S. (2007). "Behavior of stone columns based on experimental and FEM analysis". Journal of Geotechnical and Geoenvironmental Engineering. 133(4): 405-415.

Babu, M. R. D., Nayak, S. \&Shivashankar, R. (2012). "A critical review of construction, analysis and behaviour of stone columns". Geotechnical and Geological Engineering. DOI 10.1007/s10706-012-9555-9.

Barksdale, R. D. \& Bachus, R. C. (1983). "Design and construction of stone columns". Report No. FHWA/RD-83/026, National Technical Information Service. Springfield, Virginia.

Bathe, K. J., \& Wilson, E. L. (1976). “Numerical Methods in Finite Element Analysis”. Englewood Cliffs: Prentice-Hall.Black, J. A., Sivakumar, V. \& Bell, A. (2011). "The settlement performance of stone column foundations". Géotechnique. 6(11): 909-922.

Castro, J. \& Sagaseta, C. (2009). "Consolidation around stone columns. Influence of column deformation". International Journal for Numerical and Analytical Methods in Geomechanics. 33: 851-877.

Castro, J. \& Sagaseta, C. (2011). "Consolidation and deformation around stone columns: Numerical evaluation of analytical solutions" . Computers and Geotechnics. 38(3): 354362.

Castro, J. \& Sagaseta, C. (2012). "Pore pressure during stone column installation". Ground Improvement. 165(2): 97-109.

Chai, J. C., Miura, N., Kirekawa, T. \& Hino, T. (2010). "Settlement prediction for soft ground improved by columns". Ground Improvement. 163(2): 109-119. 
Cimentada, A., Costa, A. D., Canizal, J. \& Sagaseta, C. (2011). "Laboratory study on radial consolidation and deformation in clay reinforced with stone columns". Canadian Geotechnical Journal. 48: 36-52.

Deb, K. \& Dhar, A. (2011). "Optimum design of stone column-improved soft soil using multiobjective optimization technique". Computers and Geotechnics. 38(1): 50-57.

Deb, K., Samadhiya, N. K. \& Namdeo, J. B. (2011). "Laboratory model studies on unreinforced and geogrid-reinforced sand bed over stone column-improved soft clay". Geotextiles and Geomembranes. 29(2): 190-196.

Fattah, M. Y., K. T. Shlash and M. J. M. Al-Waily (2011). "Stress concentration ratio of model stone columns in soft clays". Geotechnical Testing Journal. 34(1): 1-11.

Guetif, Z., Bouassida, M. \& Debats, J. M. (2007). "Improved soft clay characteristics due to stone column installation". Computers and Geotechnics. 34(2): 104-111.

Han, J. \& Ye, S. (2002). "A theoretical solution for consolidation rates of stone columnreinforced foundations accounting for smear and well resistance effects". International Journal of Geomechanics. 2(2): 135-151.

Hanna, A., Etezad, M. \& Ayadat, T. (2013). "Mode of failure of a group of stone columns in soft soil". International Journal of Geomechanics. 13(1): 87-96.

Hird, C. C., Pyrah, I. C., \& Russell, D. (1992). "Finite element modeling of vertical drains beneath embankments on soft ground”. Géotechnique. 42(3): 499-511.

Indraratna, B., \& Redana, I. W. (1997). "Plane strain modeling of smear effects associated with vertical drains.” Journal of Geotechnical and Geoenvironmental Engineering. 123(5): 474-478.

Indraratna, B., Basack, S. \& Rujikiatkamjorn, C. (2013). "Numerical solution of stone column-improved soft soil considering arching, clogging, and smear effects". Journal of Geotechnical and Geoenvironmental Engineering. 139(3): 377-394.

Itasca (2008). “PFC2D - Particle Flow Code in 2 Dimensions, Version. 4.0”. Itasca Consulting Group. Minneapolis, MN. 
Itasca (2010). “FLAC - Fast Lagrangian Analysis of Continua, Version 6.0”. Itasca Consulting Group. Minneapolis, MN.

Juneja, A. \& Mir, B. A.(2012). "Behaviour of clay reinforced by sand compaction pile with smear". Ground Improvement. 165(2): 111-124.

Poorooshasb, H. B. \& Meyerhof, G. G.(1997). "Analysis of behavior of stone columns and lime columns". Computers and Geotechnics. 20(1): 47-70.

Schweiger, H. F. \& Pande, G. N. (1986). "Numerical analysis of stone column supported foundations". Computers and Geotechnics. 2(6): 347-372.

Sivakumar, V., Jeludine, D. K. N. M., Bell, A., Glynn, D. T. \& Mackinnon, P. (2011). "The pressure distribution along stone columns in soft clay under consolidation and foundation loading". Géotechnique. 61(7): 613-620.

Tan, S. A., S. Tjahyono, \& Oo, K. K. (2008). "Simplified plane-strain modeling of stonecolumn reinforced ground". Journal of Geotechnical and Geoenvironmental Engineering, ASCE. 134(2): 185-194.

Tandel, Y. K., Solanki, C. H. \& Desai, A. K. (2012). "Deformation behaviour of ground improved by reinforced stone columns". Australian Geomechanics: News Journal of the Australian Geomechanics Society. 47(2): 51-59. 
Table 1. Micromechanical parameters used in DEM

\begin{tabular}{l|l}
\hline Micro-mechanical parameters & Values \\
\hline Contact normal stiffness $\mathrm{k}_{\mathrm{n}}(\mathrm{N} / \mathrm{m})$ & $0.42 \times 10^{7}$ \\
Contact shear stiffness $\mathrm{k}_{\mathrm{s}}(\mathrm{N} / \mathrm{m})$ & $0.21 \times 10^{7}$ \\
Inter-particle coefficient of friction $\mu$ & 0.75 \\
Contact normal stiffness of wall-particle, $\mathrm{k}_{\mathrm{n}-\text { wall }}(\mathrm{N} / \mathrm{m})$ & $1 \times 10^{7}$ \\
Shear stiffness of wall of wall-particle, $\mathrm{k}_{\text {s-wall }}(\mathrm{N} / \mathrm{m})$ & $1 \times 10^{7}$ \\
Particle density $\left(\mathrm{kN} / \mathrm{m}^{3}\right)$ & 18.5 \\
Particle sizes $(\mathrm{mm})$ & $1.5 \div 3$ \\
\hline
\end{tabular}


Table 2. Model parameters used in FDM (FLAC)

\begin{tabular}{l|l}
\hline Materials parameters used for clay & Values \\
\hline Modulus of elasticity $E(\mathrm{kPa})$ & 4000 \\
Poison's ratio $v$ & 0.495 \\
Undrained cohesion $(\mathrm{kPa})$ & 22 \\
Undrained friction angle, $\phi_{u}($ degree$)$ & 5 \\
Density, $\gamma_{c}\left(\mathrm{kN} / \mathrm{m}^{3}\right)$ & 15 \\
Coefficient of permeability, $k(\mathrm{~m} / \mathrm{s})$ & $5.2 \times 10^{-8}$ \\
& \\
\hline
\end{tabular}

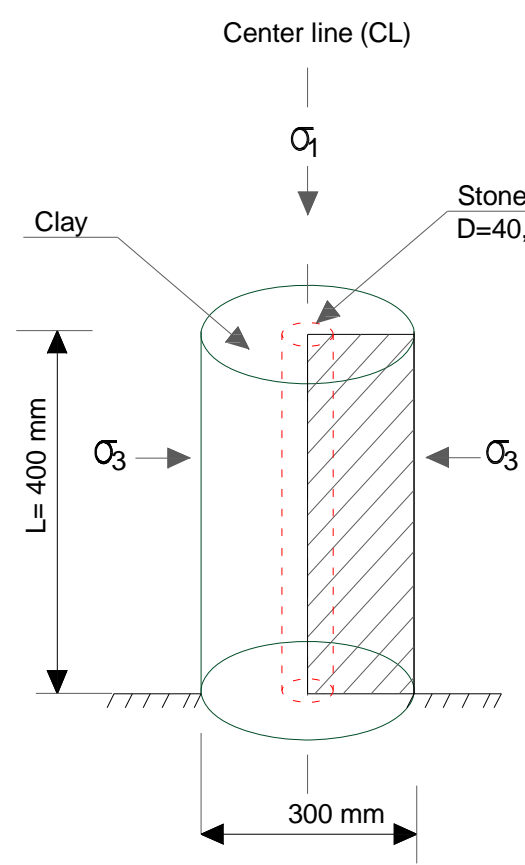

MODEL TEST

(a)
Center line (CL)

DEM-FDM Model

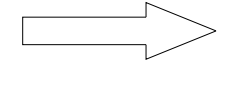

for Stone column

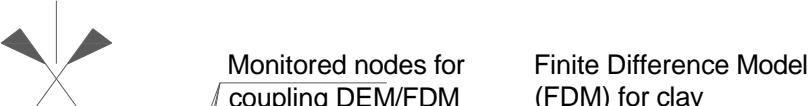

coupling DEM/FDM

(FDM) for clay

Figure 1. Conceptual model of soft clay reinforced with stone column using coupled discretecontinuum method (a) axisymmetric unit cell of stone column and (b) equivalent plane strain of mesh discretisation of stone column and surrounding clay (not to scale) 


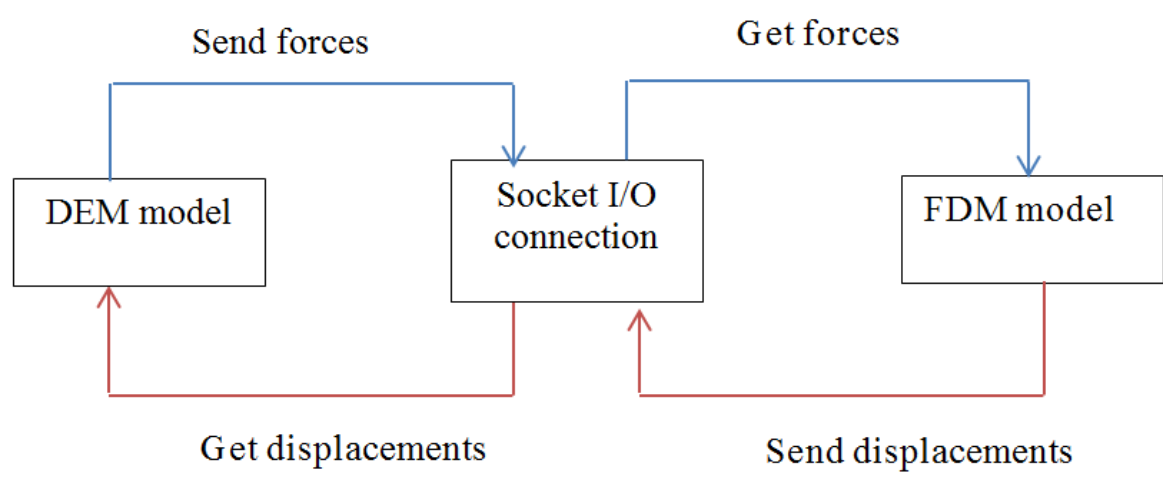

Figure 2. Data transfer between DEM and FDM via a socket connection 


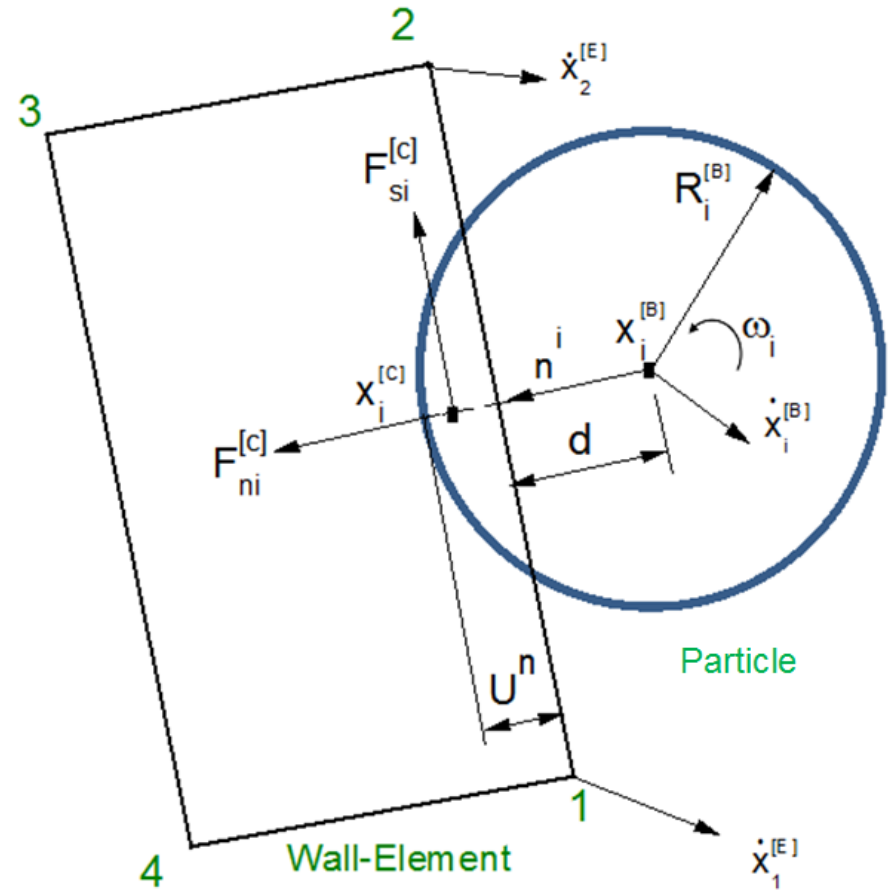

(a)

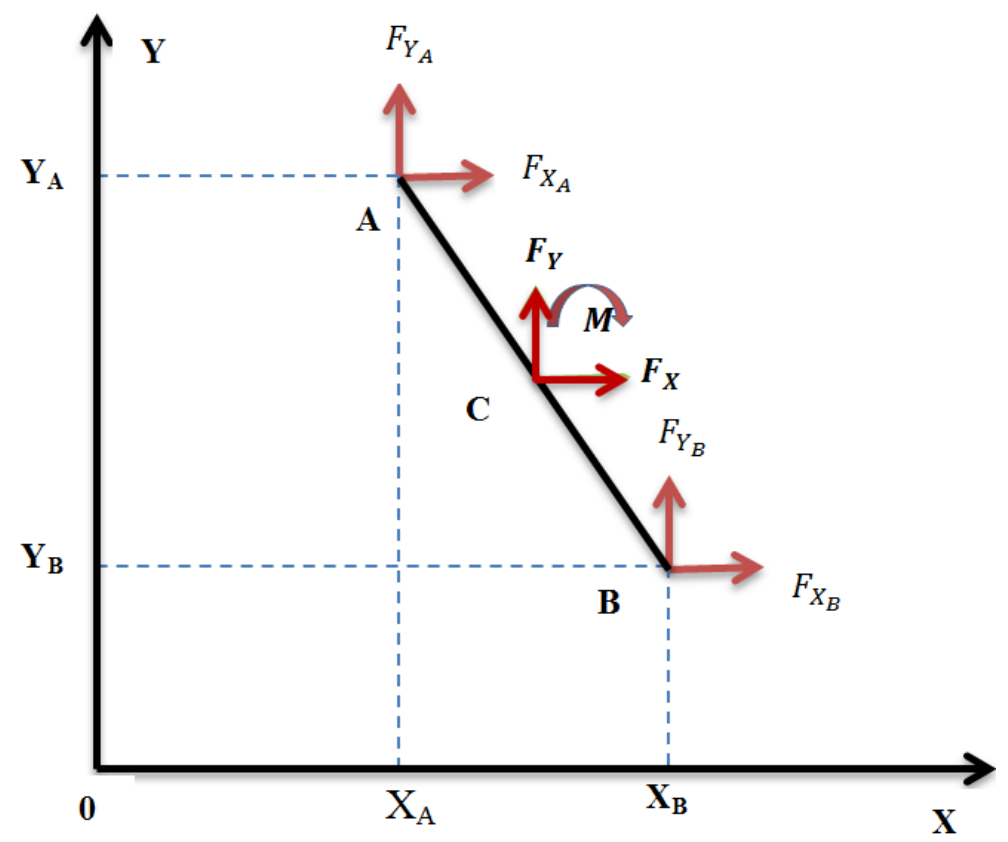

(b)

Figure 3. (a) notation used to describe the coupling mechanism between particle and continuum element; (b) schematic diagram of transferring forces and moment from DEM to FDM 


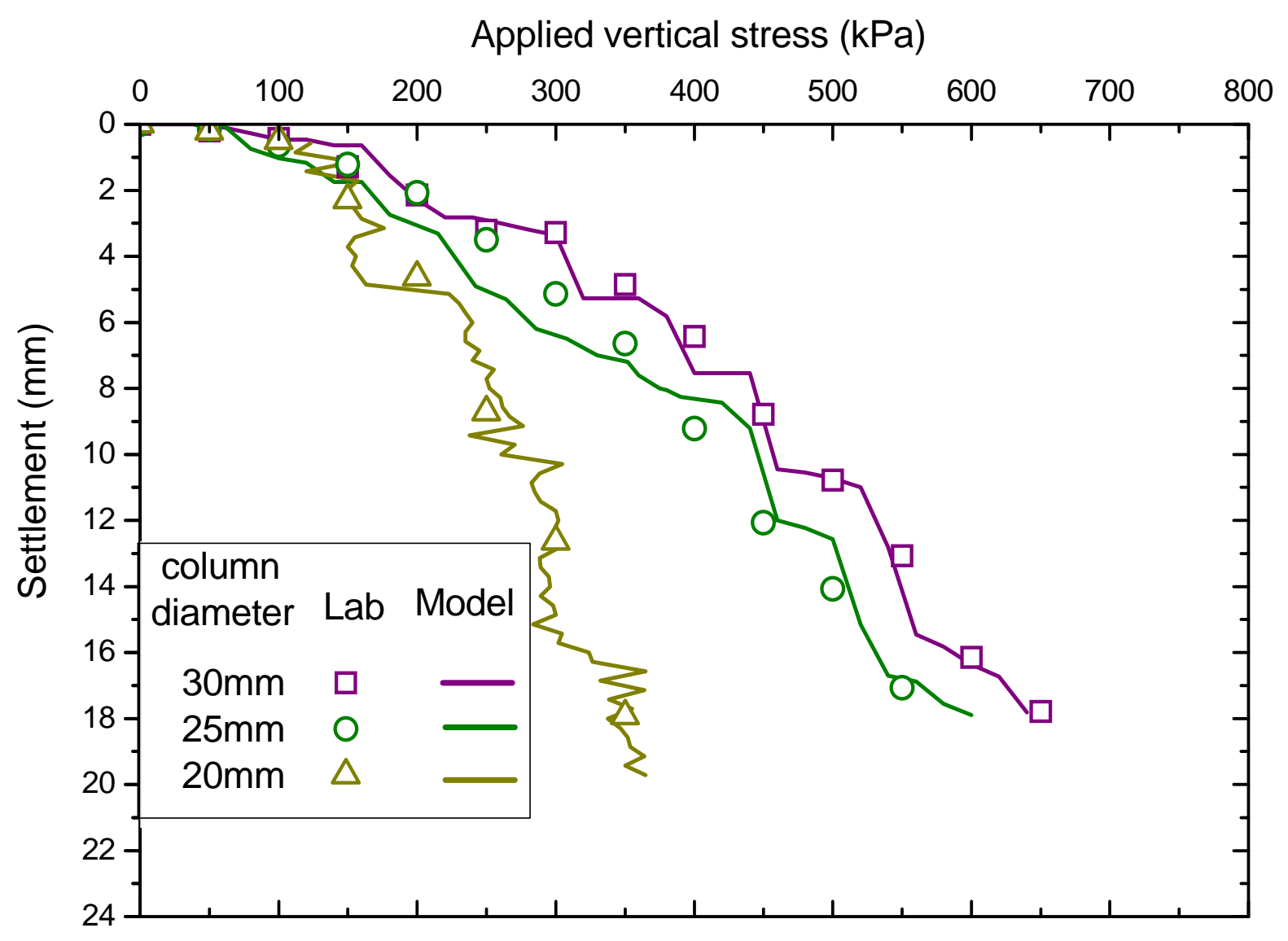

Figure 4. Comparisons of settlement versus vertical stress between the coupled DEMFDM model and experimental data by Sivakumar et al. (2011) 




Figure 5. Comparisons of vertical stress distribution at various locations for $25 \mathrm{~mm}$ diameter stone columns 


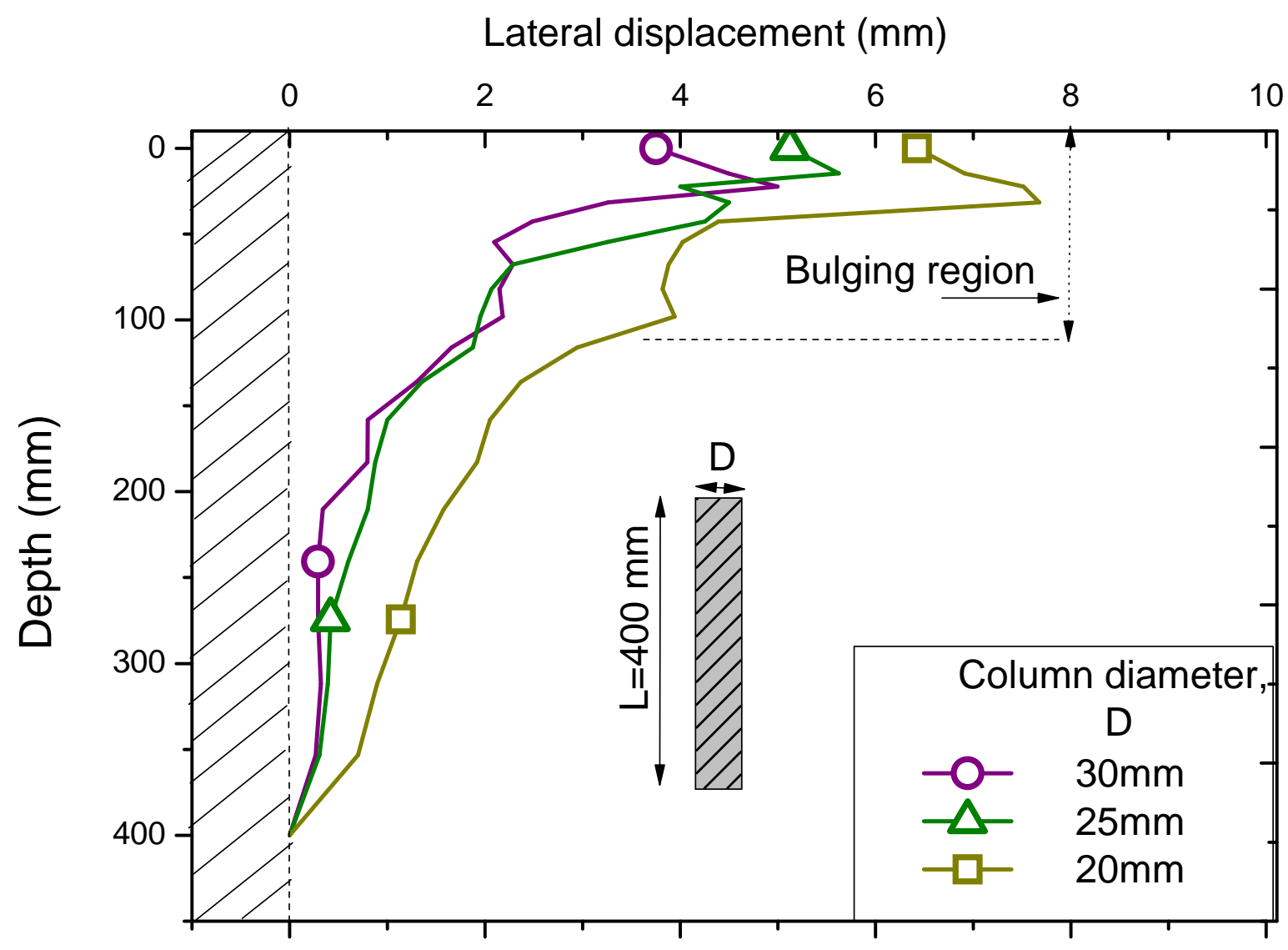

Figure 6. Predicted lateral deformation of $20 \mathrm{~mm}, 25 \mathrm{~mm}$, and $30 \mathrm{~mm}$ diameter stone columns 




Figure 7. Contact force distribution of $20 \mathrm{~mm}$ diameter stone column at varying settlements, $S$ : (a) $S=0 \mathrm{~mm}$; (b) $S=5 \mathrm{~mm}$; (c) $S=10 \mathrm{~mm}$; and (d) $S=15 \mathrm{~mm}$ 


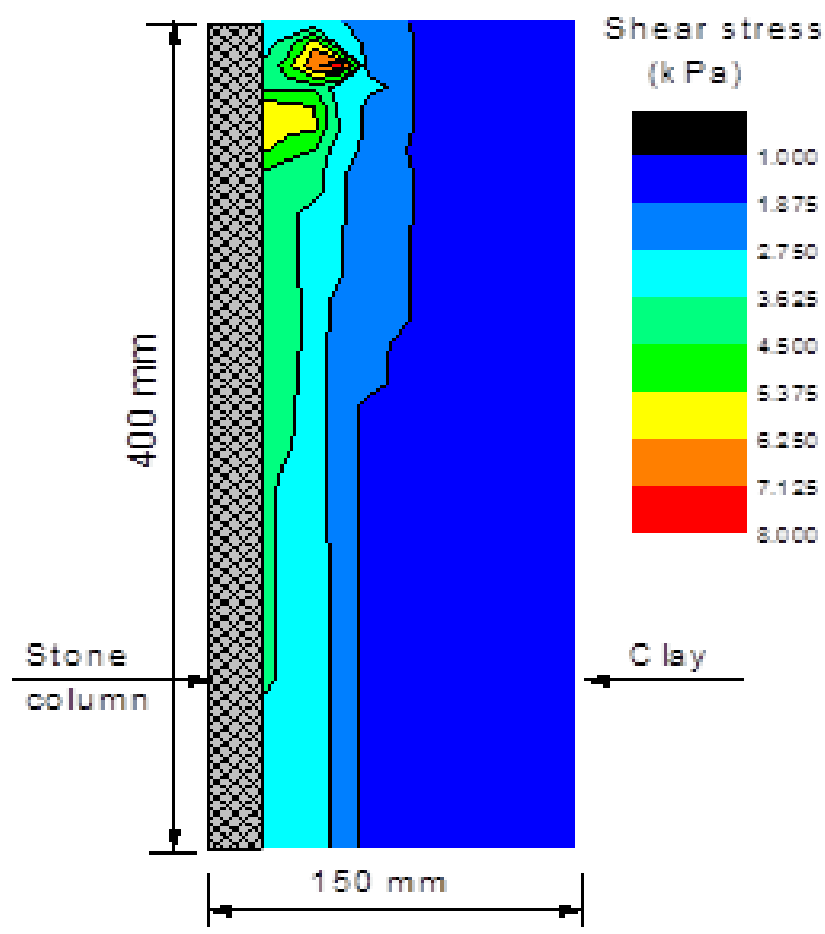

(a)

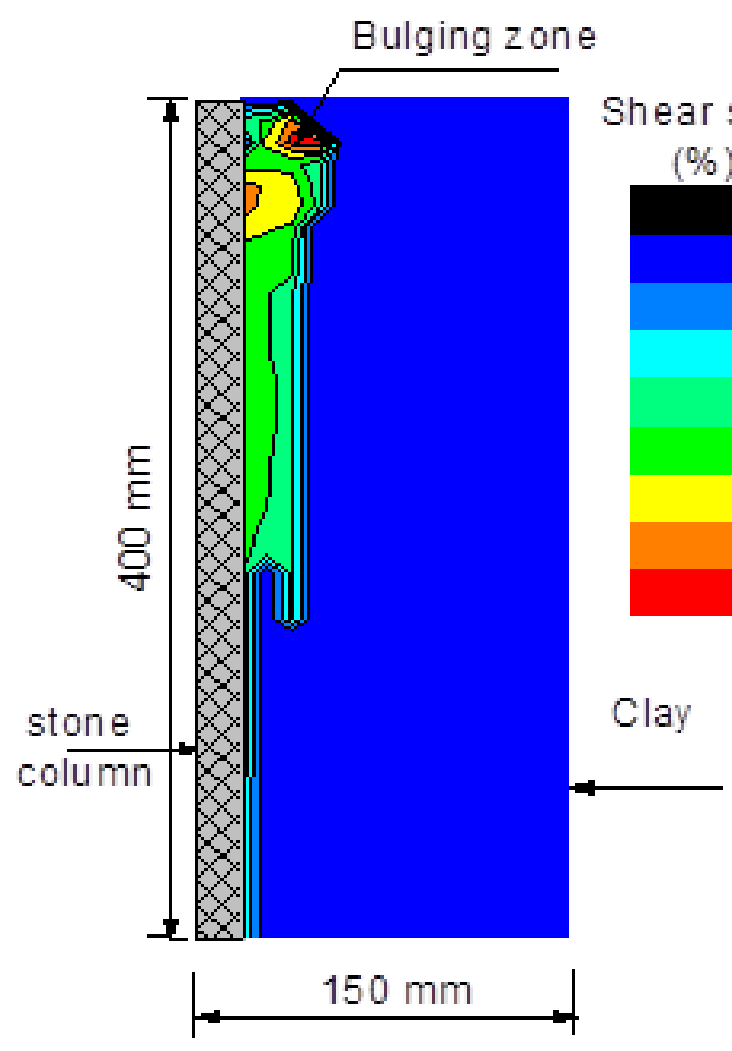

(c)

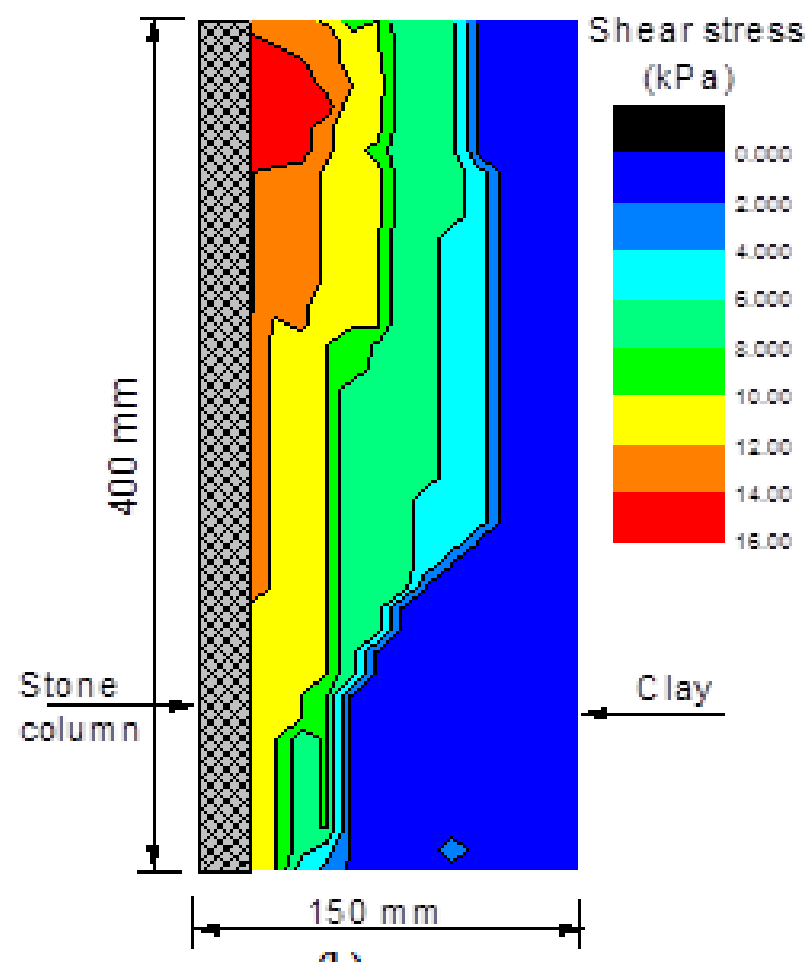

(b)

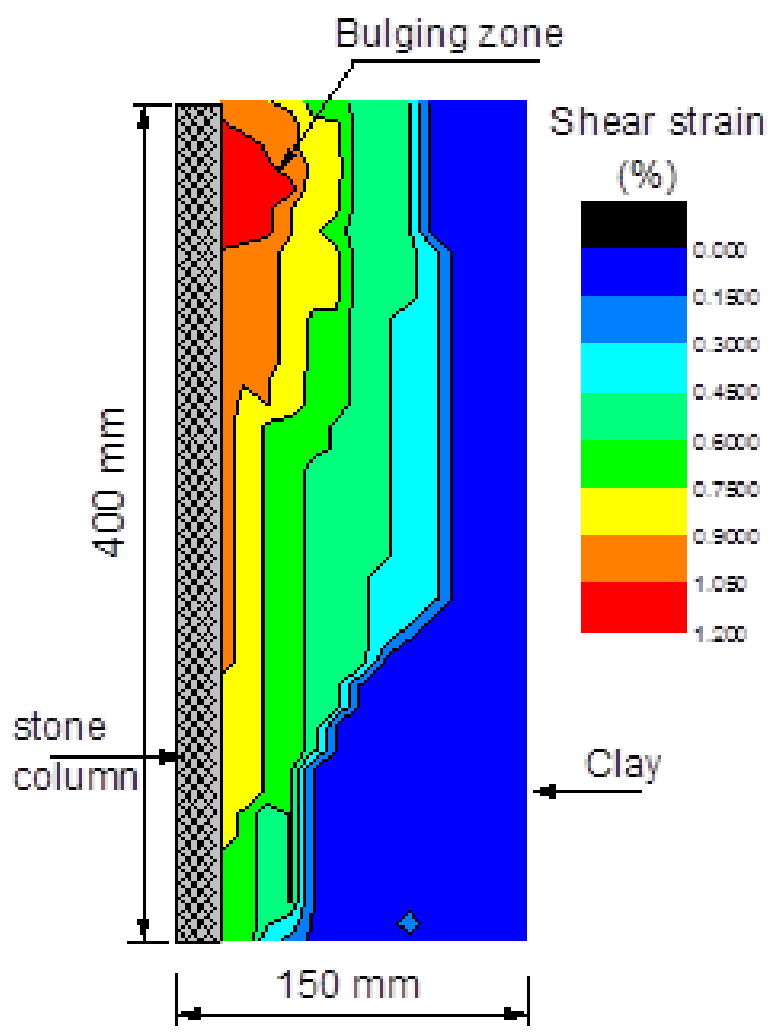

(d)

Figure 8. Shear stress-strain contour in clay stabilised by $20 \mathrm{~mm}$ diameter stone column at different settlements, $S$ : (a) and (c) shear stress, strain at $S=5 \mathrm{~mm}$; (b) and (d) ) shear stress, strain contour at $S=15 \mathrm{~mm}$ 


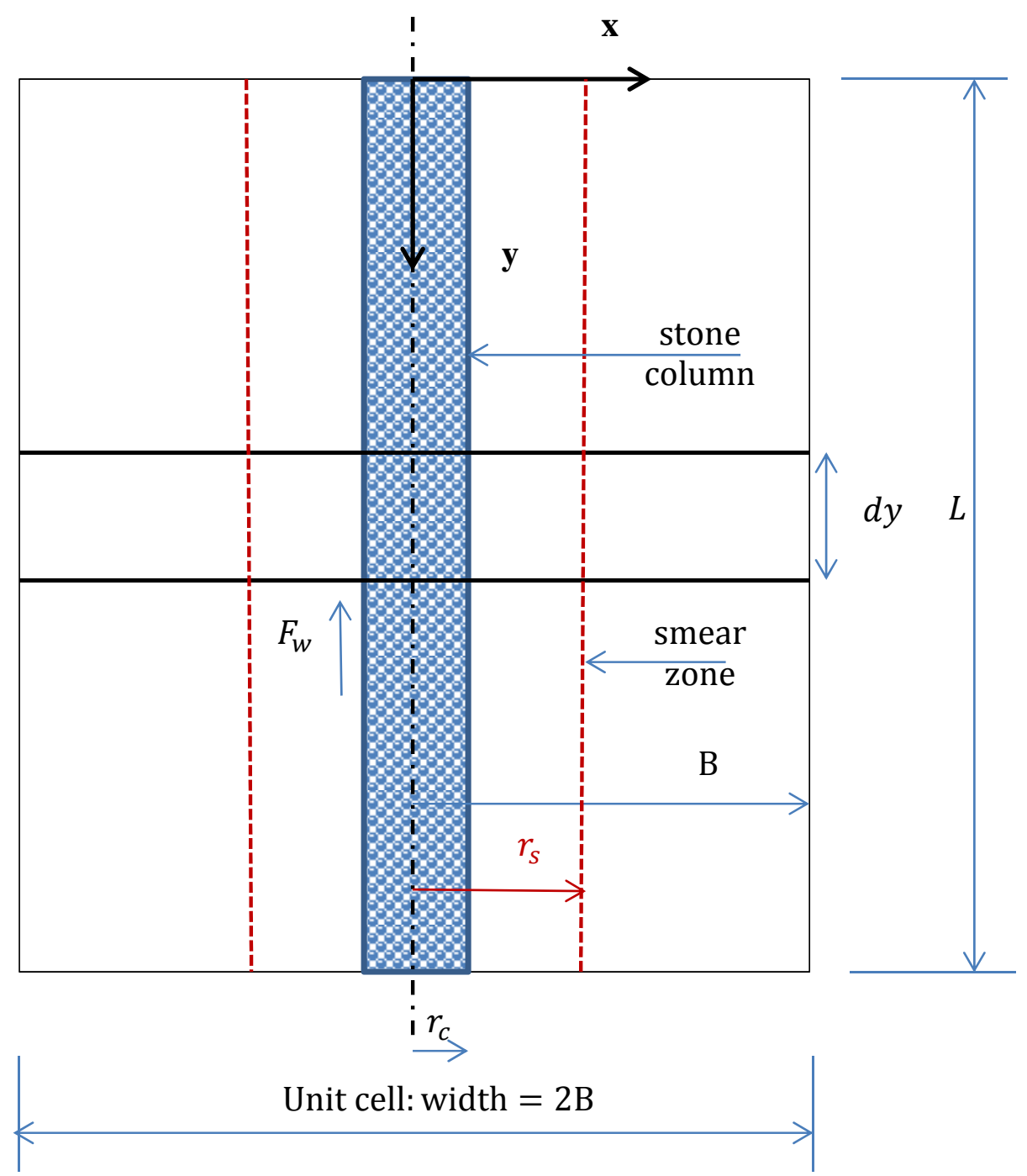

Figure 9. Plane strain unit cell 




Figure 10. Comparison of plane strain and axisymmetric results 